\title{
Téoros
}

Revue de recherche en tourisme

\section{MARTIN, Paul-Louis, et Pierre Morisset (1996), Promenades dans les jardins anciens du Québec, Boréal, Montréal, 177 p.}

\section{Kim Desjardins}

Volume 18, numéro 1, printemps 1999

Les jardins du tourisme

URI : https://id.erudit.org/iderudit/1072304ar

DOI : https://doi.org/10.7202/1072304ar

Aller au sommaire du numéro

Éditeur(s)

Université du Québec à Montréal

ISSN

0712-8657 (imprimé)

1923-2705 (numérique)

Découvrir la revue

Citer ce compte rendu

Desjardins, K. (1999). Compte rendu de [MARTIN, Paul-Louis, et Pierre Morisset (1996), Promenades dans les jardins anciens du Québec, Boréal, Montréal, 177 p.] Téoros, 18(1), 64-64. https://doi.org/10.7202/1072304ar d'utilisation que vous pouvez consulter en ligne.

https://apropos.erudit.org/fr/usagers/politique-dutilisation/ 


\section{Kim Desjardins}

MARTIN, Paul-Louis, et Pierre Morisset (1996), Promenades dans les jardins anciens du Québece, Boréal, Montréal, $177 \mathrm{p}$.

Jaquette trompeuse, le titre ramène rapidement à l'idée d'horticulture et le graphisme à l'époque romantique ; bref, du déjà vu. Par contre la photo pique la cu riosite. Qui pourrait croite que l'on possède chez nous des espaces dignes des grands jardins anglais ?

Bien au-delă du contenant, le contenu est surprenant. Davantage portés sur la notion de paysage, les auteurs nous font d'emblée revivre l'histoire du Québec à travers les divergences du regard des nouveaux arrivants et des peuples indigènes. Les explorateurs décrivaient le territoire avec des yeux d'ailleurs, un ailleurs où la nature était dominée, policée. La laideur des territoires sauvages demeura jusqu'à ce qu'on s'intéresse à la botanique et qu'on appréhende scientifiquement la flore.

Au XVIII' siècle, la perception de la nature change, elle devient paysage. La beauté du sauvage fait maintenant appel Al'émotion. Jardins anglais ou romantiques, ils seront déterminants dans l'histoire du jardin, même au Québec. Le premier chapitre est loin d'être simplement descriptif, c'est une véritable analyse de 1'époque a Une fois de plus, redisons-le, les jardins sont plus que des attributs estheriques, is expriment les visions du monde et les valeurs de ceux qui les aménagent $n$.

La deuxième partie du livre montre, en texte et en images, plusieurs jardins, dont certains sont publics et connus - comme Les Jardins de Métis, Cataraqui ou Quatre vents - et d'autres privés. Cela dit, l'accès, même livresque, ầ ces espaces interdits, éveille la curiosité. Vingt-six jardins et domaines sélectionnés sont exposés, dont huit seulement sont ouverts au public. Ce livre offre la chance unique de découvrir les plus beaux jardins et, surtout, les plus anciens. On y trouve des jardins associés à de grands noms comme Le Manoir de Louis-Joseph Papineau, Le
Domaine Mackenzie King, Le Jardin Molson, des jardins conventuels comme celui des Ursulines de Québec, des jardins très anciens comme ceux des Manoirs Saint-Ours et Greenwood, et beaucoup d'autres jardins qui accompagnent des résidences secondaires.

Contrairement à la première partie, cet inventaire ne propose pas une analyse des jardins, mais plutôt une description historique et physique de ceux-ci. Chacun des jardins est un récit en soi et la quantité de documentation sur le sujet, en plus des images exceptionnelles, en fait un ouvrage de référence. Accessible autant au professionnel qu' à l'amateur, ce volume modifie de façon étonnante notre regard sur les jardins du Québee.

Kim Desjardins es étudiante à la maîtrise en paysage à la Faculte de lamenagement de P'Universite de Montreal. 